\title{
The reflective journal: A tool for enhancing experience- based learning in nursing students in clinical practice
}

\author{
Bagnato Silvia ${ }^{1}$, Dimonte Valerio², Garrino Lorenza² \\ 1. Mauriziano Ospedale Umberto I, Turin, Italy. 2. University of Turin, Turin, Italy.
}

Correspondence: Bagnato Silvia. Address: AO Mauriziano Ospedale Umberto I, Via Magellano 1, 10100 Turin, Italy. Telephone: 39-115-082-767. Email: silvia.bagnato@katamail.com.

Received: June 30, 2012

DOI : $10.5430 /$ jnep.v3n3p102
Accepted: August 22, $2012 \quad$ Online Published: November 19, 2012

URL: http://dx.doi.org/10.5430/jnep.v3n3p102

\section{Abstract}

Background: As a tool for documenting and accompanying students' actions, the journal has an educational value: it can be used to record, recollect and re-elaborate experiences through a reflective, non-intimate writing. The study was carried out at the Degree Course in Nursing at the University of Turin (Italy), during a training period of six weeks at the Unit of Functional Reeducation of the hospital "M. Adelaide - C.T.O.”. The aim is to understand the level of reflection that students can reach using the journal and what they think about this experience in terms of learning opportunity.

Methods: The group of thirteen students in second and third year graduation course was invited to write daily, for fifteen consecutive days, a journal that describes their experience in training. Subsequently, the journals were analyzed with a qualitative method based on the seven levels of reflectivity that Mezirow had proposed within the transformative theory applied to adult learning. After this first phase, the group of students was invited to take part in a focus group to share and discuss their experience. The focus group was designed in semi-structured form. Qualitative content analysis was used to identify themes arising from the data.

Results: Twelve journals were analyzed. Students have reflective ability, especially with respect to Mezirow's first three levels. The main findings showed that keeping a journal helps students to effectively enhance their experiential learning during the training period. For the focus group six students were involved. The following themes emerged: embarrassment and uneasiness, anonymity, evaluation, efficacy of the tool in experiential learning.

Conclusions: The study enriches the debate on the use of journals confirming what has already been described in literature with respect to journals potential in terms of fostering and stimulating a professional practice of a reflective type.

\section{Key words}

Clinical practice, Journals, Nursing education, Reflective learning

\section{Introduction}

Professional learning is a complex process consisting of cognitive, behavioral, relational and emotional aspects, in which experience is given a prominent role. As a privileged place for learning, experience sets off one's actions, increases knowledge and contributes to the construction of a personal identity through critical reflection ${ }^{[1-3]}$. 
Reflective thinking, initially theorized by John Dewey, was developed by Donald Schön who determined two levels of reflection: "thinking of what one is doing" and "thinking thoughts". The first level, in particular, is called reflective action and enhances the role of reflection that takes place during the action (reflection-in-action) and retrospectively (reflection-on-action). For Schön the basic characteristic of professionals is their ability to reflect on their experience and learn from it ${ }^{[4,5]}$. An important contribution to the value of reflection in adult learning comes from Mezirow's transformative theory ${ }^{[6]}$. According to Mezirow, every individual attributes meaning to an event through a process of interpretation; the relationship every individual has with the outside world is closely linked to previous personal experiences.

Learning is equivalent to "finding meaning" and always implies the schematization and embodied new experience. In this perspective, recollection acquires a considerable relevance, because it enables us to learn from old interpretations that became rooted in our minds (critical working-through of an experience) and re-use new interpretations in analyses, judgments and generalizations. Learning implies construction and approval of an interpretation that determines action. Experience in the field, typical of nurses' training, is full of life experiences, relational dynamics, expectation and emotions that inevitably come into play during learning. But it can be difficult in practice to set aside some time to devote to "thinking". So there is the risk that past experiences tend to leave no signs behind them and do not provide useful traces for reflective thinking. Resorting to writing enables to retain and maintain one's own experience. The use of journals as an educational technique for documenting and accompanying students' actions is interesting from an educational standpoint because its object is the writer's experience ${ }^{[7]}$. So, the journal becomes an opportunity for the writer to learn something about himself. Compared to the intimate diary, in the reflective journal the writer starts from experience to come back to it later; along this path, the journal can be seen as a bridge. In the exact moment the writer reflects on what happened, the journal stands as a tool for the author's self-reflection, both on himself and on his relations with the others. Through the journal, reflectivity on experience mutates into self-reflection and the journal experience becomes a form of critical and reflective experience with the others ${ }^{[3-8]}$.

In some of the described experiences, the use of journals was effective in different domains such as nurses sharing and exchanging the experience of critical events, promoting the reflective thinking during the training period of a group of students, and as a tool used by a group of tutors who experimented its educational potential in the clinical practice from the perspective of both students and trainers ${ }^{[9-12]}$. In journal writing, the events are reported on sheets of paper, notebooks and journals while they are occurring. After having seen, listened to, acted and met the others for a few moments, students can re-elaborate their experiences in the journal, ask questions and try to find answers; it becomes a self-reflective opportunity. Therefore, journals can be used to prevent a memory or an experience from being lost. Used with students as an educational tool, such journals make the described experiences available for reflection and future access ${ }^{[13]}$. In this case, journals are meant as a reflective tool rather than an autobiographical or introspective expression. It is a tool through which the writer - when rereading the account - can see what happened and how he/she dealt with it. The distance between the reading ego and the writing ego creates astonishment in writers rereading what they have written, bringing them to discover a new truth or a new aspect of themselves and of their own narrated experience.

Journals then provide an opportunity to learn something about oneself. Compared to the intimate ones, reflective journals start from experience to return to it: in this way they work as a link. When the reflection on an event begins, the journal becomes an opportunity to reflect on oneself and also on one's relationships with the others. Reflecting on experience becomes reflecting in the experience: in this way the experience of the journals becomes an experience of emotional, critical and reflective relationships with the others ${ }^{[3]}$.

Considering reflectivity as a skill that contributes to the ability to form a critical professional conscience capable of questioning the meaning of the experience, journals become a narrative practice that uses the subject, the experience and the relationships with the others to build the meaning of one's own experience ${ }^{[14]}$. 
Starting from the conceptual context described, the role of educators and tutors becomes crucial in leading students to reflect on experience. Since practice requires students to face complex situations, it is particularly important to analyse the meaning of experience in depth and highlight those experiences that play a specific role and the reason behind this. Through the use of journals, tutors can accompany students in reflecting on their own experience during the reading stage ${ }^{[12-15]}$. Before introducing journal writing to students, it should be considered how to analyze their stories. Assuming a certain level of unavoidable subjectivity from the reader, a tool to overcome this difficulty is needed. In a 1995 study described by Richardson and Maltby, the instrument used for the analysis is based on the levels of reflection proposed by Mezirow ${ }^{[16]}$.

The study's aim was to understand the level of reflection that students during their training period in rehabilitation ward can reach using the journal and what they think about this experience in terms of learning opportunity.

\section{Methods}

The research was conducted at the Unit of Functional Reeducation of the hospital "M. Adelaide - C.T.O.” in Turin (Italy). In the Unit there are twenty-two beds for patients with an outcome of traumatic brain injury, amputation and burns, who require second and third level rehabilitation. The internship period lasts six weeks. The group of students in second and third year graduation course was invited to write daily, for 15 consecutive days, a journal that describes their experience in training. All the students - twelve women and only one man - whose average age was 23 (range 22-30) accepted. Participants in this research project were all volunteers and they were kept anonymous.

Subsequently, the journals were analyzed with a qualitative method based on the seven levels of reflectivity that Mezirow had proposed within the transformative theory applied to adult learning. Powell adapted the levels of reflectivity to a study on a group of nurses to evaluate reflectivity in nursing practice ${ }^{[6,17]}$. Richardson and Maltby then re-proposed the tool used by Powell (1989) to analyse the journals of a group of students during a training period ${ }^{[16]}$. A grid was built on 7 levels: it contained the description of each level and was used to analyse the students' journals written between March and December 2009 (see Table 1).

Table 1. Mezirow’s seven levels of reflectivity ${ }^{[16]}$

\begin{tabular}{|l|l|}
\hline \multicolumn{2}{|l|}{ Levels of consciousness } \\
\hline $\begin{array}{l}\text { Level } 1 \\
\text { Reflectivity }\end{array}$ & $\begin{array}{l}\text { This refers to students' awareness of a specific perception, behaviour, habit, experience and } \\
\text { ability to describe it. }\end{array}$ \\
\hline $\begin{array}{l}\text { Level } 2 \\
\text { Affective reflectivity }\end{array}$ & This represents students' ability to recognize and express their feelings or those of others. \\
\hline $\begin{array}{l}\text { Level } 3 \\
\text { Discriminant reflectivity }\end{array}$ & $\begin{array}{l}\text { This refers to students' ability to evaluate processes of decision-making, planning or } \\
\text { evaluation of activities undertaken during the training period. }\end{array}$ \\
\hline $\begin{array}{l}\text { Level } 4 \\
\text { Judgmental reflectivity }\end{array}$ & $\begin{array}{l}\text { Students are aware of expressing evaluation judgments subjective in nature that can } \\
\text { influence practical actions. }\end{array}$ \\
\hline Levels of critical consciousness \\
\hline $\begin{array}{l}\text { Level } 5 \\
\text { Conceptual reflectivity }\end{array}$ & This represents the ability to recognize the need for improving their skills. \\
\hline $\begin{array}{l}\text { Level } 6 \\
\text { Psychic reflectivity }\end{array}$ & $\begin{array}{l}\text { Students recognize that they tend to express rash judgments on other people based on } \\
\text { limited information. }\end{array}$ \\
\hline $\begin{array}{l}\text { Level } 7 \\
\text { Theoretical reflectivity }\end{array}$ & $\begin{array}{l}\text { This includes several elements: awareness that routine or certain fixed practices may not be } \\
\text { the proper response in a specific situation; learning following a specific event; a change of } \\
\text { perspective, since students follow the perspective that best suits to the situation. }\end{array}$ \\
\hline
\end{tabular}




\section{Data analysis}

Each journal was identified by a number and read for a first time to identify its general meaning; after that, it was read again in order to identify, using the grid, the levels of reflectivity achieved in every narrated episode. After this second reading, it was read a further two times in order to identify levels that may have been omitted in the previous analysis.

Each journal was tabulated, describing for each narrated episode the following aspects:

- The level of reflectivity achieved;

- The text revealing the identified level;

- The date on which the episode was written.

Finally, for each journal the identified levels and their recurrence were reported in a summary table. The analyses were carried out individually by two of the authors (S.B. and L.G..) and themes, categories and codes were then compared and discussed. The group of students was invited to take part in a focus group to share and discuss their experience. The focus group was designed in semi-structured form, so discussions were guided by some questions prepared beforehand. The entire meeting was recorded with the participants' prior consent. This made it possible to re-listen and transcribe the entire focus group discussion. Subsequently, the transcription was analyzed to identify the opinions expressed and summarize the meeting. Qualitative content analysis was used to identify themes arising from the data ${ }^{[18]}$. The study participants were informed about the study purpose and the need for audio-taping. They were informed that participation was voluntary and they were assured confidentiality. All participants gave their verbal consent.

\section{Results}

Thirteen journals were written by second and third year nursing students. Twelve journals were analyzed because one of them included only drawings and could not be analysed according to the chosen method.

Table 2 lists the levels and extent of reflectivity for each student. On the whole, 459 reflectivity levels were identified, with a range for each student included between 11 scores (journal n.12) and 101 (journal n.7)

Table 2. Reflectivity levels in students' journal

\begin{tabular}{|c|c|c|c|c|c|c|c|c|}
\hline Journal & Lev. 1 & Lev. 2 & Lev. 3 & Lev. 4 & Lev. 5 & Lev. 6 & Lev. 7 & Total \\
\hline 1 & 21 & 4 & 5 & 0 & 0 & 0 & 0 & 30 \\
\hline 2 & 16 & 6 & 3 & 2 & 1 & 1 & 4 & 33 \\
\hline 3 & 20 & 4 & 5 & 0 & 1 & 0 & 1 & 31 \\
\hline 4 & 10 & 4 & 5 & 0 & 1 & 0 & 2 & 22 \\
\hline 5 & 11 & 0 & 1 & 0 & 1 & 0 & 1 & 14 \\
\hline 6 & 12 & 2 & 1 & 0 & 0 & 0 & 2 & 17 \\
\hline 7 & 44 & 19 & 26 & 4 & 4 & 0 & 4 & 101 \\
\hline 8 & 19 & 10 & 13 & 1 & 6 & 0 & 3 & 52 \\
\hline 9 & 47 & 12 & 17 & 1 & 3 & 0 & 1 & 81 \\
\hline 10 & 14 & 10 & 8 & 1 & 1 & 0 & 1 & 35 \\
\hline 11 & 16 & 6 & 8 & 0 & 2 & 0 & 0 & 32 \\
\hline 12 & 7 & 3 & 0 & 0 & 0 & 0 & 1 & 11 \\
\hline 13 & 0 & 0 & 0 & 0 & 0 & 0 & 0 & 0 \\
\hline \multirow{2}{*}{ Totals } & 237 & 80 & 92 & 9 & 20 & 1 & 20 & 459 \\
\hline & $51.63 \%$ & $17.43 \%$ & $20.04 \%$ & $1.96 \%$ & $4.36 \%$ & $0.22 \%$ & $4.36 \%$ & $100 \%$ \\
\hline
\end{tabular}


The lowest levels are preponderant. Level 1 of reflectivity is the most frequent (237 scores), followed by level 3 of discriminant reflectivity (92), level 2 of affective reflectivity (80). Level 5 of conceptual reflectivity and level 7 of theoretical reflectivity have been attained 20 times each, while only in one case was level 6 of psychic reflectivity achieved.

All levels from 1 to 7 were identified at least once in one case only (journal n.2), while only one student failed to go beyond level 3 (journal n.1); 5 students showed all the primary consciousness levels, while 10 achieved levels 5 and 7, included in critical consciousness, at least once. One student failed to go beyond level 2, attaining level 7 only once (journal n.12).

In Level 1, identified repeatedly in all journals, the students' situations and experiences during the training period were described. Descriptions refer to:

- The atmosphere among patients: “...the situation was beautiful, cheered up by the smiles that escape from the lips of people who, due to their life story, are sometimes unable to be so spontaneous...” (journal n.2);

- A specific moment when assisting a patient: “...I spent the morning holding a patient's hand... at the end, she thanked me...” (journal n.5);

Reaching Level 2, students described their feelings relating to a specific experience during the training period:

- "...It was so moving that, at one point, I ran out of the room because I could no longer hold back my tears..." (journal n.3);

- “...I felt I was choking; anxiety was growing; the situation was more serious than expected...” (journal n.7).

Many students achieved level 2, describing feelings that they recognized in patients:

- “...in my opinion she is upset about the accident she had and actually I would be upset, too...” (journal n.10);

Level 3, identified in many recounted episodes, demonstrated the students' ability to evaluate:

- The activities carried out during the training period:

"...today has been a great day; I have managed to get organized and spend some time with all the patients. Excellent I would say...” (journal n.4);

- The effectiveness of communication with patients :

“...I don't know if they were the right words, but then he smiled at me...” (journal n.7);

"...What did we do then? We tried to reassure her, pointing out that she would get all she needed before leaving and then she could call the ward and talk to us or the physicians about anything she needed, any doubt or difficulty. She seemed more confident...” (journal n.7);

- The efficacy of a caring action:

“...that morphine had no effect on her; she was feeling less pain...” (journal n.8);

“...I did an extemporaneous catheterization today; things went well...” (journal n.11). 
In Level 4, seldom identified in the students' journals, some situations were described in which personal judgment had an influence on:

- Expectations: “...it is simple for us since we are in this field, but taking care of a critical patient for someone who has a completely different job can cause fear and anxiety...” (journal n.9);

- Judgments on some people: “...I hate the kind of people who compare their vagaries with the real problems that can be encountered in life...” (journal n.2).

Level 5, rarely identified, demonstrates that some students perceive the need to develop certain abilities to improve learning:

• “...I know I’m not so good in situations like that, but I hope to learn little by little...” (journal n.7);

- “...I also have another task: to go and check the joints because I don't remember them well; in fact M. questioned me about joints and I didn't know them...” (journal n.11).

The student in whose journal Level 6 was identified admitted he expressed a rash judgment on other people and he had to change his mind during the real experience:

- “...thinking about the type of patients, I wondered 'what chaos would be mobilizing them' ... and then you realize that they do everything almost by themselves ...” (journal n.2).

In the few cases in which Level 7 was identified, students reported reflections on the inappropriateness:

- Of certain behaviour: “...how many times I heard say and I said (I'm also to blame): I go to number 15 or check that number 3's drip is finished. But who's number 3 or 15? Sometimes we don't even remember why they are hospitalized...” (journal n.2);

- Of some theoretical solutions: “...M., how can your left foot hurt? It’s gone; so how can it make you suffer? I know the scientific explanation: but what use is it to you?” (journal n.12).

For the focus group we managed to contact ten of the thirteen students involved; six of them were willing to participate. From the discussion and the debate the following themes emerged:

1) Embarrassment and uneasiness: were expressed by students as they wrote, thinking about the reader. Students had read the journals with a tutor or in a group, and the prevailing feeling was embarrassment in writing it and thinking someone would read it. They also felt uneasy at being compelled to write. Another student described embarrassment because of nurses' curiosity as to the content of the journal.

2) Anonymity: some students assert that anonymity of the journals would ensure greater freedom in expressing and describing their experiences; they all agreed, however, that it is impossible to grant anonymity in a small group like the study group, since the number of students is so small everyone can be identified. This leads some students to omit certain descriptions, to not be honest.

3) Evaluation: students feel that journals should not be taken into account during evaluation, because there is the concrete risk that tutors may be influenced by what they read. In fact one student asserted: "If I read something, it obviously influences me somehow or other!" 
4) Efficacy of the tool in experiential learning: one student reported that writing was useful to vent anger and the journal helped manage it: "Sometimes I vented my anger by writing on the sheet of paper instead of venting it on somebody else and everything stopped. It helped me to continue my day". One student stressed that "keeping a journal should be recommended and not required". Another agreed with that, but pointed out that tutors should not read the journals but simply ask students whether they found it useful without getting to the heart of the content. Another student declared: "In my opinion the problem is that the journal provides no tangible help for students. It's a piece of paper: I help myself. What kind of help is it?” Referring to this declaration, other students proposes the presence of another person who does not belong to the tutors' group and serves as reference for students if they need to express their emotions, doubts and critical aspects of the situations experienced.

Some said the journal was useful to describe new learning experiences: "I spoke about the team meeting: it was something new, different from routine”.

\section{Discussions}

This study showed that all students had reflective ability according to Mezirow's levels ${ }^{[6]}$. As in the studies described by Richardson and Maltby and Powell, the first three levels of Mezirow's scale are the easiest to reach ${ }^{[6,13,16]}$. Their higher recurrence reveals that students describe the meaning of their experiences, recognize both their own feelings and those of the people involved and are capable of evaluating the efficacy of planned actions. Thanks to this specificity of students' writing, their accounts are valuable contributions to subsequent reflection, which, if tutor-guided, can create opportunities for learning from past experience. Students cease to be the authors of an narrated episode and become the makers of a reflective process that helps them think about what they are doing. The ability to describe situations, perceptions and experiences allows one to "put ones' knowledge into action" [19].

Students described their feelings or recognized somebody else's feelings in achieving affective reflectivity. This reflectivity level plays an essential role because, by recognizing one's own or somebody else's feelings, a person becomes aware they both belong to the same emotional world.

On the contrary, some students used the journal as a place for "venting" emotions with a liberating effect. One of them said: “...it led me to resolve the situation in a different way." In this case, writing could be interpreted as the place where the cure is described, but ultimately it is an opportunity for taking care of oneself. Writing can give voice to a feeling, an emotion, as well as making it possible to relive, understand and recognize them.

The description of both students and patients' prevailing feelings can become a form of sharing.

Idczak described how it can be possible to recognize, through the journal, the feelings that characterize the relationship between the nurse and the patient, and how this aspect can improve the learning of the student ${ }^{[20]}$. Tutors acting as learning facilitators have a crucial role in this sense and can obviate the feeling of loneliness previously described by one student. If students are left alone with their journals, there is the risk of cancelling the tool's potential for reflection and learning.

Within this path, the tutoring may contribute to the development of the student's reflective skills, supporting him through the most critical phases ${ }^{[15]}$. This creates between the tutor and the student a close interaction, strongly characterized by a relational dimension which is the process of learning from experience. An educational relationship is established, characterized by reflection and reduced asymmetry, in a listening atmosphere focused on the learner ${ }^{\text {[21] }}$. Some authors argued that, by inviting students to tell and tell about themselves, it is possible to recognize "how they learn during learning" by implementing a metacognitive process ${ }^{[22]}$. Analysis of the journals confirms this assumption. In fact, the decision to describe the most significant episodes of the internship, as stated in some focus groups, allowed the reader to 
investigate retrospectively the peculiar aspects of the clinical experience. The diary turns into a communication tool with each other and themselves.

Attaining the discriminating and conceptual reflectivity levels (Level 3) provides useful incentives for reflecting on the journal's use. In fact, as Richardson and Maltby's study showed, some students appreciated the opportunity to evaluate their progress during the training period. Not award reflectivity (Level 3) shown by students could be very useful in self-learning evaluation ${ }^{[16]}$. The evaluation of a caring action or the outcome of a planned action came up repeatedly in the journals; this should help students define other educational needs or verify performance levels in certain domains. Furthermore, considering some students' conceptual reflectivity, it is also possible to hypothesize a genuine contribution to students' learning that can help them redefine their educational contract. For instance, in intermediate evaluation, rereading journals could highlight the need to reformulate certain areas of learning.

The difficulty in achieving levels 5 and 7, however, as already reported in the other studies, could give tutors the idea of promoting reflection, classified as critical conscience.

The level of psychic reflectivity (Level 6), not attained by most of the sample, implies an ability to analyse relationships with others. Boosting such reflection would be interesting because it highlights how judgments are expressed and also affords an opportunity to think about how to establish relations with the others. Critical reflection on this issue could improve self-knowledge.

Theoretical reflectivity (Level 7), achieved by very few students, led us to identify from the narrated events the students' ability to use their knowledge, apply it to experiences and verify whether it is appropriate or not in the situations they underwent. The result is the completion of the learning path that approaches theory ${ }^{[6]}$. The ability to achieve this level of reflectivity could certainly be due to individual characteristics, demonstrating that, while some of those who have it should be stimulated to develop it further, others require assistance to attain this level. As pointed out by Jensen and Joy, students should be helped to improve their reflective abilities ${ }^{[23]}$.

Journal analysis certainly demonstrated the students' reflective ability, but a further opportunity for evaluating the tool was offered through focus groups in which students were able to exchange ideas: some interesting topics arising from the discussion should be carefully taken into account when deciding to use the journal experience with students.

As an example, embarrassment could be reduced by making the journal optional. Students could be left free to decide whether or not to use it: thus, the journal would no longer be perceived as mandatory. In that way, resorting to writing is a need more than something mechanical or imposed.

In the focus group, anonymity emerged as an important issue. The anonymity seems to acquire special value when related to the evaluation, which was a recurrent subject for debate. In fact, the fear of evaluation could inhibit the development of the abilities required by reflection. Since students expressed the same concern in the Richardson and Maltby's study, authors suggested creating a neutral atmosphere to reflect with students, in order to establish a climate of confidence in which students can focus on their experience ${ }^{[16]}$. The two researchers also point out that journals should not be used for evaluation, but rather as a personal recording tool for students to begin talking with themselves, tutors and other students. Douchet \& Wilson emphasize peer sharing of what is written in the journals, showing how this method can both improve critical thinking and collaboration between students and promote the planning of nursing interventions based on newborn ideas ${ }^{[24]}$. The same authors also emphasize that reading the journals once again with the tutor, in groups or individually, brings out positive, problematic and emotional issues, and that a further analysis can foster a new, additional learning ${ }^{[12-25]}$.

Fonteyn \& Cahill stated that writing has proved effective in enhancing active learning, encouraging reflection and improving metacognitive skills (the ability to think about one's thoughts) ${ }^{[21]}$. These capabilities are the foundation of 
critical thinking and this study, highlighting the reflective abilities of students, helps to promote reflective writing as a tool to enhance experience ${ }^{[26]}$.

Passing from non-knowledge to knowledge, the subject experiences the uncertainty of the unknown. Going through this indefinite space separating the subject from knowledge creates a cognitive and emotional uneasiness that must be well tolerated to achieve learning. Thanks to journals, meant as tools to maintain the feelings and emotions that characterize every contact with yet-unknown reality, tutors can help students cope with the unavoidable uneasiness that arises in the initial learning stage and be able to use it for growth potential.

\section{Conclusions}

This study contributes to the debate on the use of journals not only because it confirmed what had already been described in the literature on its value, but also because it helped to reveal the reflective ability of students who keep journals. Journals analysis using Mezirow's reflectivity levels was useful to achieve the set objectives or to answer the need for analysing journals in an attempt to reduce the subjectivity of readers as much as possible ${ }^{[6]}$.

The elements of reflection provided by the study show that this experience can be further improved. Although this was a first and experimental stage both for students and tutors, it is important to emphasize that this study led to confirm what the literature had already pointed out: journals reveal students' reflective ability. Taking into account the critical aspects and the improvements indicated by the students, journal writing is considered to be a valuable tool to enhance students' experiential learning. Further contributions could enrich the current debate.

\section{References}

[1] Boud D. Using journal writing to enhance reflective practice. New directions for adult and continuing education. 2001; 90: 9-17. http://dx.doi.org/10.1002/ace.16

[2] Lyons J. Reflective education for professional practice: discovering knowledge from experience. Nurse Educ Today. 1999; 19: 29-34. PMid:10222968 http://dx.doi.org/10.1054/nedt.1999.0607

[3] Lethbridge K. Reflection on reflection - A response to Dr. Burnard’s. Nurse Educ Today. 2006; 26: 263-267. PMid:16624456 http://dx.doi.org/10.1016/j.nedt.2006.02.011

[4] Schon DA. The Reflective Practitioner: how professionals think in action. New York: Basic Books, 1983.

[5] Schon, DA. Educating the Reflective Practitioner. San Francisco: Jossey-Bass Inc, 1987.

[6] Mezirow J. Transformative Dimensions of Adult Learning. San Francisco: Jossey-Bass Inc, 1991.

[7] Harris M. Scaffolding reflective journal writing- Negotiating power, play and position. Nurse Educ Today. 2008; 28: 314-326. PMid:17698259 http://dx.doi.org/10.1016/j.nedt.2007.06.006

[8] Duffy A. Guiding students through reflective practice-The preceptor experience. A qualitative descriptive study. Nurse Education in Practice. 2009; 9: 166-175. PMid:18768370 http://dx.doi.org/10.1016/j.nepr.2008.07.002

[9] Craft M. Reflective writing and nursing education. J Nurs Educ. 2005; 44: 53-57. PMid:15719711

[10] Chirema K. The use of reflective journals in the promotion of reflection and learning in post-registration nursing students. Nurse Educ Today. 2007; 27: 192-202. PMid:16815600 http://dx.doi.org/10.1016/j.nedt.2006.04.007

[11] Montagna L, Benaglio C, Zannini L. Reflective writing in nursing education: background, experiences and methods. Assist Inferm Ric. 2010; 2: 140-152.

[12] Zannini L, Cattaneo C, Brugnolli A, Saiani L. How do healthcare professionals perceive themselves after a mentoring programme? A qualitative study based on the reflective exercise of "writing a letter to yourself”. J Adv Nurs. 2011; 10: 1-11.

[13] Epp S. The value of reflective journaling in undergraduate nursing education: a literature review. Int J Nurs Stud. 2008; 45: 1379-1388. PMid:18325522 http://dx.doi.org/10.1016/j.ijnurstu.2008.01.006

[14] Peden-McAlpine C, Tomlinson PS, Forneris SG, et al. Evaluation of reflective practice intervention to enhance family care. J Adv Nurs. 2005; 49: 494-501. PMid:15713181 http://dx.doi.org/10.1111/j.1365-2648.2004.03322.x

[15] Bev W. Developing critical reflection for professional practice through problem-based learning. J Adv Nurs. 2001 ; 34 : 27-34. http://dx.doi.org/10.1046/j.1365-2648.2001.3411737.x 
[16] Richardson G, Maltby H. Reflection on practice: enhancing student learning. J Adv Nurs. 1995; 22: 235-242. PMid:7593942 http://dx.doi.org/10.1046/j.1365-2648.1995.22020235.x

[17] Powell JH. The reflective practitioner in nursing. J Adv Nurs. 1989; 14: 824-832. PMid:2808937 http://dx.doi.org/10.1111/j.1365-2648.1989.tb01467.x

[18] Hsieh HF, Shannon SE. Three approaches to qualitative content analysis. Qual Health Res. 2005; 15: 1277-1288. PMid:16204405 http://dx.doi.org/10.1177/1049732305276687

[19] Mann K, Gordon J, Mac Leod A. Relection and reflective practice in health professions education: a systematic review. Adv Health Sci Educ Theory Pract. 2009; 14: 595-621. PMid:18034364 http://dx.doi.org/10.1007/s10459-007-9090-2

[20] Idczak S. I am a nurse: Nursing students learn the art and science of nursing. Nurs Educ Perspect. 2007; 28: 66-71. PMid:17486794

[21] Claudette K. Student's perceptions of effective clinical teaching revisited. Nurse Educ Today. 2007; 27: 885-892. PMid:17321013 http://dx.doi.org/10.1016/j.nedt.2006.12.005

[22] Fonteyn M, Cahill M. The use of clinical logs to improve nursing student's metacognition: a pilot study. J Adv Nurs. 1998; 28: 149-154. PMid:9687142 http://dx.doi.org/10.1046/j.1365-2648.1998.00777.x

[23] Jensen S, Joy C. Exploring a model to evaluate levels of reflection in baccalaureate nursing students'journals. J Nurs Educ. 2005; 44: 139-142. PMid:15787024

[24] Douchet C, Wilson S. A three step method of self reflection using reflective journal writing. J Adv Nurs. 1997; 25: 964-968. http://dx.doi.org/10.1046/j.1365-2648.1997.1997025964.x

[25] Mantzoukas S, Jasper M. Reflective practice and daily ward reality: a covert power game. J Clin Nurs. 2004; 13: 925-933. PMid:15533098 http://dx.doi.org/10.1111/j.1365-2702.2004.01008.x

[26] Wall C, Glenn S, Mitchinson S, Poole H. Using a reflective diary to develop bracketing skills during a phenomenological investigation. Nurse Res. 2009; 11: 4-6. 